\title{
Editor-in-Chief: Benjamin Bonavida
}

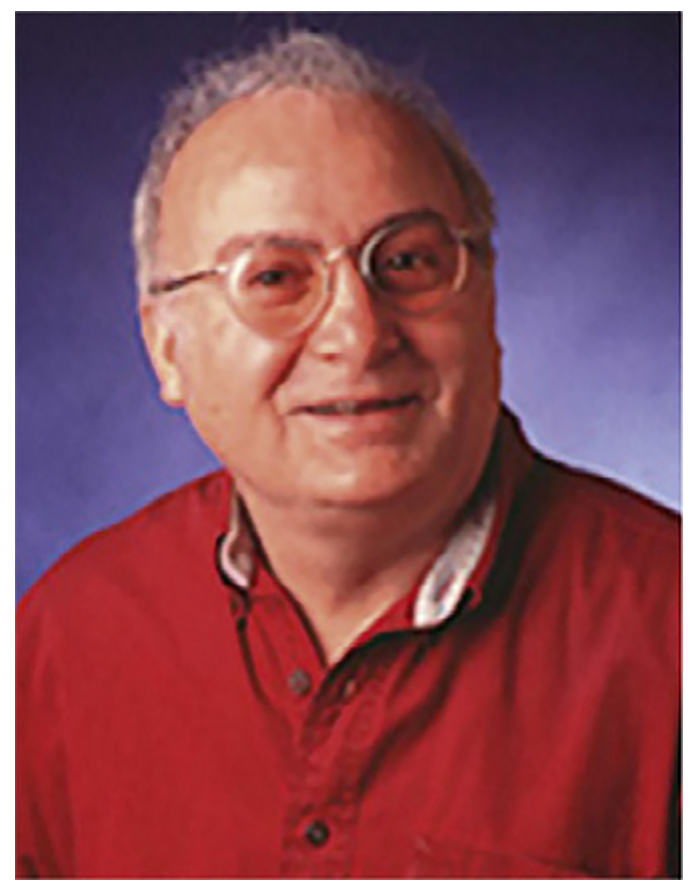

Benjamin Bonavida, $\mathrm{PhD}$, is currently serving as Distinguished Research Professor at the University of California at Los Angeles (UCLA), and is affiliated with the Department of Microbiology, Immunology and Molecular Genetics in the UCLA David Geffen School of Medicine. His research career thus far has focused on basic immunochemistry and cancer immunobiology, with investigations ranging from the biochemical, molecular, and genetic mechanisms of cell-mediated killing to tumor cell resistance to chemoimmuno-cytotoxic drugs. His research on reversal of tumor cell resistance involved selected sensitizing agents based on molecular mechanisms of resistance. These investigations revealed that the newly characterized dysregulated NF- $\kappa \mathrm{B} / \mathrm{Snail} /$ YY1/RKIP/PTEN loop regulates cell survival, proliferation, invasion, metastasis, and resistance in many cancers, with emphasis on the tumor suppressor Raf kinase inhibitor protein (RKIP), the tumor promoter Yin Yang 1 (YY1), and the role of nitric oxide as a chemoimmuno-sensitizing factor. Much of Dr. Bonavida's research centers on the clinical challenges of resistance to both conventional and targeted therapies in cancer patients.

Dr. Bonavida has been active in organizing international mini-conferences, and he has edited or co-edited several books. He served as series editor of Resistance to Anti-Cancer Targeted Therapeutics (Springer), and he is presently series editor of Chemotherapy-Sensitizing Agents for Cancer, Breaking Tolerance to Anti-Cancer Antibodies Therapy, and Breaking Tolerance to Anti-Cancer Immunotherapy (Elsevier/Academic Press). Dr. Bonavida is the associate editor of the journal Critical Reviews ${ }^{\mathrm{TM}}$ in Immunology (Begell House). He has published over 500 research papers and reviews in various scientific journals of high impact.

The excellent editorial assistance of Ms. Inesa Navasardyan, who worked diligently on both the editing and the formatting of the various contributions to this volume, is gratefully acknowledged. Ms. Navasardyan, who recently graduated from UCLA, contributed a review chapter to this volume on triple negative breast cancer. Also gratefully acknowledged is the Department of Microbiology, Immunology and Molecular Genetics in the UCLA David Geffen School of Medicine for its continued support. 